ЛЮБОВ ПРОКОПІВ, кандидат педагогічних наук, доцент, кафедра педагогіки та освітнього менеджменту імені Богдана

Ступарика, доцент ДВНЗ "Прикарпатський національний університет імені Василя Стефаника", Украӥна ORSID ID 0000-0001-8661-510x

Liubov.prokopiv@pnu.edu.ua

ОКСАНА СИДОРУК, викладач української мови та літератури, завідувач відділення дошкільної освіти, Івано-Франківський фаховий коледж ДВНЗ "Прикарпатський національний університет імені Василя Стефраника", Украӥна ORSID ID 0000-0002-7173-5798

Oksana.sydoruk@pnu.edu.ua

\title{
ВИКОРИСТАННЯ ІННОВАЦИЙНИХ ТЕХНОЛОГІЙ НАВЧАННЯ ЯК ЕФЕКТИВНОЇ КОМУНІКАЦІЇ В ОСВІТНЬОМУ ПРОЦЕСІ ЗАКЛАДУ ВИЩОї ОСВІТИ
}

LIUBOV PROKOPIV, phD in Education, Associate Professor, Bohdan Stuparyk Department of Pedagogy and Educational Management, Vasyl Stefanyk Precarpathian national university, Ukraine

OKSANA SUDORYK, Lecturer in Ukrainian Language and Literature, Head of the Preschool Education of Ivano-Frankivsk Professional College, Vasyl Stefanyk Precarpathian national university, Ukraine

\section{USING INNOVATIVE EDUCATIONAL TECHNOLOGIES AS EFFECTIVE COMMUNICATION IN THE EDUCATIONAL PROCESS AT HIGHER EDUCATION INSTITUTIONS}

Стаття присвячена дослідженню питання впровадження інноваційних технологій навчання у практику роботи ЗВО задля ефективної комунікації студентів. Автором виділено найбільш поширені технології інноваційного навчання та засвоєння мовної компетентності студентів. У роботі використано теоретичні методи педагогічної реконструкції, репрезентативне онлайн-опитування на основі системи LimeSurvey.

Ключові слова: інновації, комунікація, соціокультурна компетентність, онлайн-середовище, веб технології, студентське середовище.

Summary. The article deals with the research of the introduction of innovative educational technologies into the activities of higher education institutions for the purpose of effective communication with students. The study highlights the most common technologies of innovative learning and building students' language competence. The paper uses theoretical methods, methods of pedagogical

(C) Л. Прокопів, О. Сидорук reconstruction, representative on-line survey based on the LimeSurvey system. The results obtained confirmed the feasibility of introducing innovations into the activities of higher education institutions .

Key words: innovation, communication, sociocultural competence, students' environment, effective communication.

Мета: обгрунтувати можливості використання інноваційних підходів до реалізації ефективного комунікування в закладах вищої освіти.

Постановка проблеми в загальному вигляді. На сучасному етапі розвитку нової української освіти перспективним $є$ пошук інноваційних шляхів її здобугтя. У зв'язкуз європейським вектором iï спрямування потребують змін підходи до навчання студентської молоді.

Для розв'язання завдань дослідження використано метод педагогічної реконструкції, фокусовані інтерв'ю зі студентами, SWOT-аналіз оцінки сильних і слабких сторін у використанні інноваційних технологій навчання.
Сучасні дослідження свідчать, що інструментом створення та інтерпретації "образу світу", проникнення у світову культуру й усвідомлення своєї національної приналежності, соціальної взаємодії, формування і соціалізації особистості є мова. Одне 3 ключових завдань сучасної вищої освіти в умовах сучасного інноваційного простору, у тому числі й дистанційного, виступає формування мовної культури особистості, котра володіє фаховими компетентностями, що сприяють розвитку взаємостосунків, взаєморозумінню і повазі, а також забезпечують володіння технологіями усного й писемного спілкування різними мовами. Усі ці фактори становлять комунікативну й соціокультурну компетентності.

Це ставить перед закладами вищої освіти (далі - 3ВО) завдання переосмислення і реорганізації підходів до змісту та технологій навчання.

Аналіз досліджень і публікацій. Необхідність інноваційного підходу до освітнього процесу підтверджується на законодавчому рівні. Це стосується всіх 3ВО, у тому числі й педагогічних. Проблему інноватики 
в міжкультурному просторі розглядають чимало вчених - як зарубіжних (М. Байрам, Б. Бонні, Б. Брік, Л. Каснер та ін.), так і українських (Т. Бойко, О. Будник, I. Дичківська, I. Підласий, М. Чепіль Л. Шевчук та ін).

Зокрема, В. Авраменко, Л. Паркета переконують, що саме завдяки впровадженню інновацій "студенти отримують теоретичні знання: міжособистісного пізнання та міжособистісних стосунків; законів логіки й аргументації; професійного, у тому числі мовного, етикету; культури вербальної і невербальної взаємодії" (Авраменко \& Пархета, Л, 2019, с. 12).

Дослідниця інновацій у галузі іноземної мови Т. Близнюк переконує, що "діджиталізація всіх сфер суспільства та популярність інформаційних технологій у світі зайняли чільне місце в освітньому секторі" (близько 19\%) (Близнюк, 2019, с. 93).

У зв'язку з європейським вектором розвитку сучасної вищої освіти потребують змін підходи до навчання студентської молоді. Перспективним сьогодні бачиться пошук інноваційних шляхів ефективної комунікації. Ця розвідка $є$ продовженням циклу публікації авторів (Прокопів \& Корчига, 2018).

Виклад основного матеріалу дослідження. На сучасному етапі побутує чимало думок $з$ приводу ефективної комунікації як складової культури особистості. Нам імпонують визначення культури в англійському тлумачному Кембриджському словнику: the customs, beliefs, art, music, and all the other products of human thought made by a particular group of people at a particular time :ancient Greek culture, a tribal culture, pop culture. (Культура - звичаї, вірування, мистецтво, музика та інші плоди людської думки певної групи людей в певний час) (Cambridge Advanced Learner's Dictionary \& Thesaurus). Результатом діалогу культур є розуміння і прийняття відмінностей між людьми іншої культури, запозичення цінностей їх духовного і матеріального життя, установлення міжкультурної комунікації, які проаналізуємо детальніше.

Наші дослідження ми зіставляли 3 апробованими технологіями в сучасній американській освіті.

Для нашої роботи важливо розуміти поняття "інновація". На переконання Б. Бонні, "Innovatio" як ідея або концепція призначена зробити або ввести щось краще (більш ефективне, приємніше, корисніше), здатність адаптувати технологію для задоволення індивідуальних потреб, а не навпаки (Bonnie, 1992, p. 23).

Н. Кайда, Л. Касснер та ін. застосовують такі терміни для визначення інновації: "революційний", "руйнівний", "нерегулярний" або "відкриття". Інновації збільшили нашу продуктивність порівняно з попередніми поколіннями і принципово змінили спосіб та всі аспекти нашого життя. Важливим фактором ефективної комунікації $є$ застосування нових технологій у навчанні: критичного мислення, проєктної діяльності, ігрові; викладач розвиває інтерес до мови і для спілкування.

Ми погоджуємось 3 думкою Л. Шевчук, що термін "нові технології" включає в методи комунікації, де вирішальну роль відіграє комп'ютер (Шевчук, 2013, с. 119). Однак є інші технологічні інструменти. Кожен 3 них має свої конкретні переваги у формуванні та застосуванні одного з чотирьох аспектів (мовлення, аудіювання, читання та письма). Щоб упроваджувати їх, майбутній викладач повинен бути ознайомлений 3 використанням інноваційних технологій, зокрема сучасних гаджетів та Інтернету, під час вивчення як рідної, так і іноземної мов, а також здатним взаємодіяти з цими методами.

Проаналізуємо ці технології детальніше. На сучасному етапі комп'ютеризації неабияке місце для професійного розвитку студентів має електронне навчання (elearning), яке включає в себе мультимедійне, віртуальне, комп'ютерне, мобільне на- вчання. Так, Б. Брік стверджує, що завдяки новим 3МI та глобалізації відбувається стиснення часу і простору, і світ зменшився в мале інтерактивне поле (Brick, 2012, p. 41), створилось так зване "глобальне село", де люди різних культур комунікують. Це дозволяє студентам використовувати соціальні мережі, щоб знаходити собі друзів, встановлювати та підтримувати стосунки. Такі мережі сприяють не тільки обміну культур з представниками інших націй, а й дають змогу покращити знання іноземної мови за допомогою онлайн-чатів та онлайн-розмов 3 носіями іноземної мови. Н. Брукс пояснює, що соціальні мережі завдяки онлайн-технологіям роблять вивчення другої мови більш соціальним, 3 мінімальним стресом, та підкреслює важливість соціальних медіа як електронного інструменту, який $є$ прогресивним у процесі вивчення іншої мови (Brooks, 1968, p. 206). Таким чином можна покращити рівень рецептивних (прослуховування і читання) і продуктивних (мовлення та письмо) мовних навичок. Це підтверджує визначення Т. Хатчінсона, що соціальні мережі - це соціальні середовища, створені для тих, хто хоче взаємодіяти з людьми та легко вивчати мову (Hutchinson \& Waters).

Задля визначення можливостей використання соціальних мереж студентами Івано-Франківського фахового коледжу та педагогічного факультету ДВНЗ "Прикарпатський національний університет імені Василя Стефаника" нами проведений контент-аналіз (близько 300 респондентів), що показав найбільш поши-

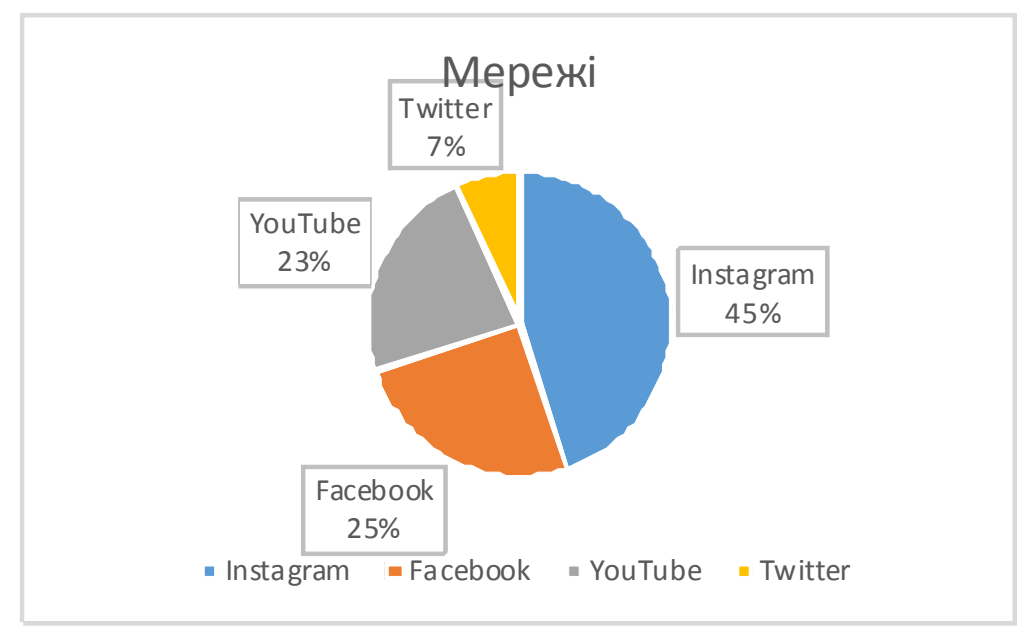

Рис. 1. Поширені типи соціальних медіа серед студентської молоді 
рені типи соціальних медіа та мережевих сайтів - Instagram, Facebook, YouTube, Twitter (див. puc. 1.).

Спробуємо пояснити даний факт і проаналізуємо детально ці мережі.

Так, допомогою Instagram (www.instagram.com) $є$ можливість розвивати візуальне мислення, а за допомогою хештегів студенти можуть знаходити друзів. Важливим у Facebook є, здебільшого, неформальне спілкування (писемне чи усне). Молодь вдало використовує інформацію у спеціальних групах та спільнотах мережі і, таким чином, ознайомлюється з різними культурами. Так, існує певний позитивний вплив на їх мотивацію - це виконувати вправи в середовищі соціальної мережі Facebook, брати участь у онлайн-розмовах, у виконанні домашнього завдання тощо.

Орієнтовні завдання, спрямовані на ефективну комунікацію в цій мережі, розроблені нами (Табл. 1).

Користувачі

YouTube (www.youtube.com) можуть переглядати і коментувати ті чи інші відеозаписи. На практичних заняттях цю мережу доцільно використовувати 3 метою пошуку чи створення навчальних відео. Дана технологія відіграє важливу роль у вивченні іншої мови шляхом електронного збільшення контактів з широким спектром автентичних матеріалів, адже перегляд іншомовних відео, прослуховування аудіоматеріалів та навіть ведення власного онлайн-каналу безперечно покращують засвоєння іноземної мови.

Популярними в наш час є мовні лабораторії (language lab) - аудіо- та відеовізуальні системи, які допомагають студентам вивчати мови, ефективно комунікувати слухаючи та роз- мовляючи. Зокрема, K-VanSolutions (http://www.kvansol.com) - це програмне забезпечення, яке найкраще підходить студентам, адже додаток орієнтований на професійне вивчення рідної та іноземної (англійської) мов. Відома сучасна мовна лабораторія використовує аудіоаналіз для порівняння речення студента та викладача, а також для виправлення вимови. ODLL (http://languagelab.in/aslsoftware) - мовна лабораторія ODLL - зосереджується на спільному навчанні, пропонуючи способи об'єднання студентів, спілкування з деякими або всіма учнями одночасно $\mathrm{i}$ навіть проведення звичайного заняття в лабораторії. ODLL підтримує відео цифрових (наприклад, YouTube) або аналогових (DVD) джерел.

Як показала практика, комп'ютерне (Computer-Assisted Language

Таблиия 1

\section{Ст ворення власних просктів у соціальних мережах}

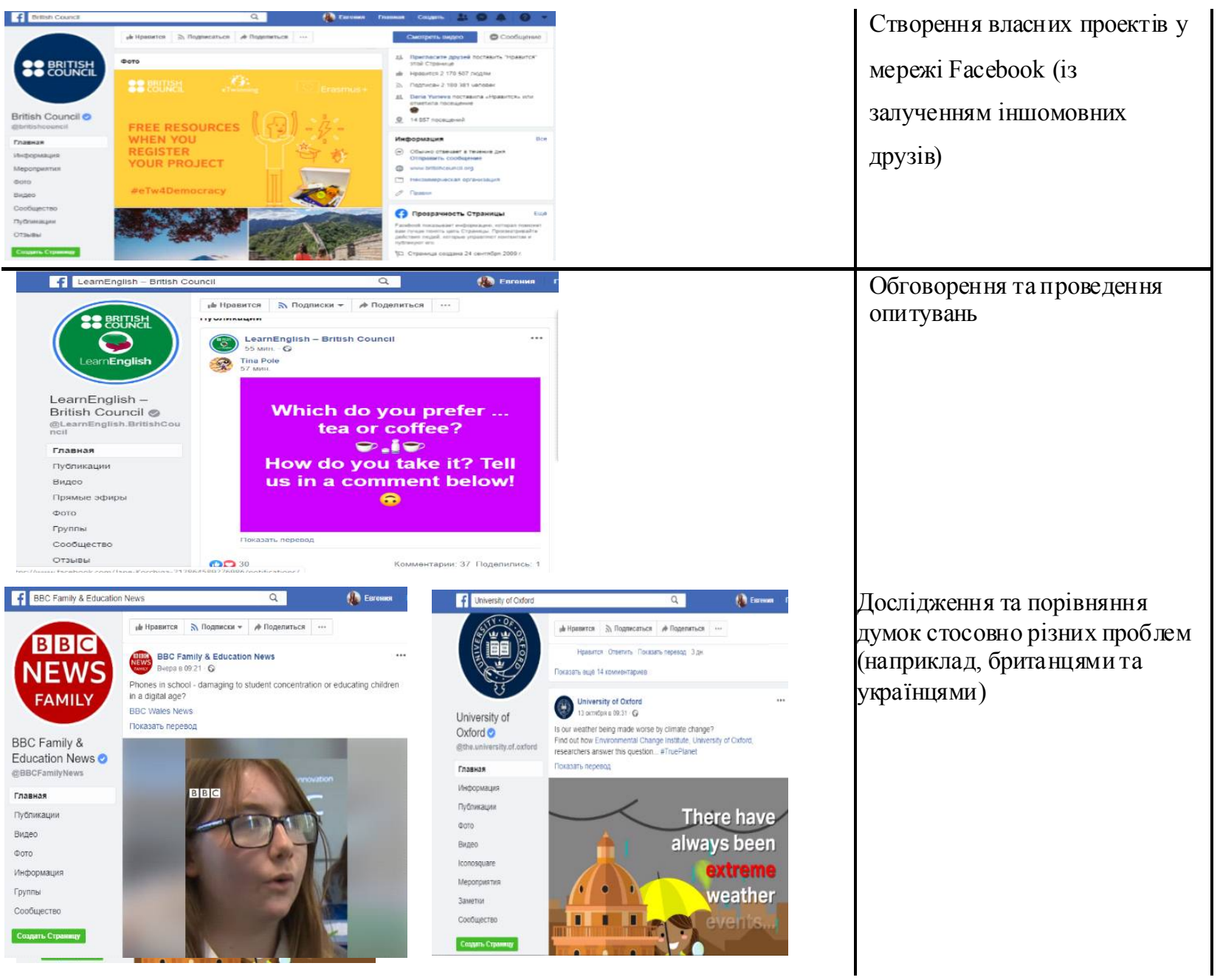




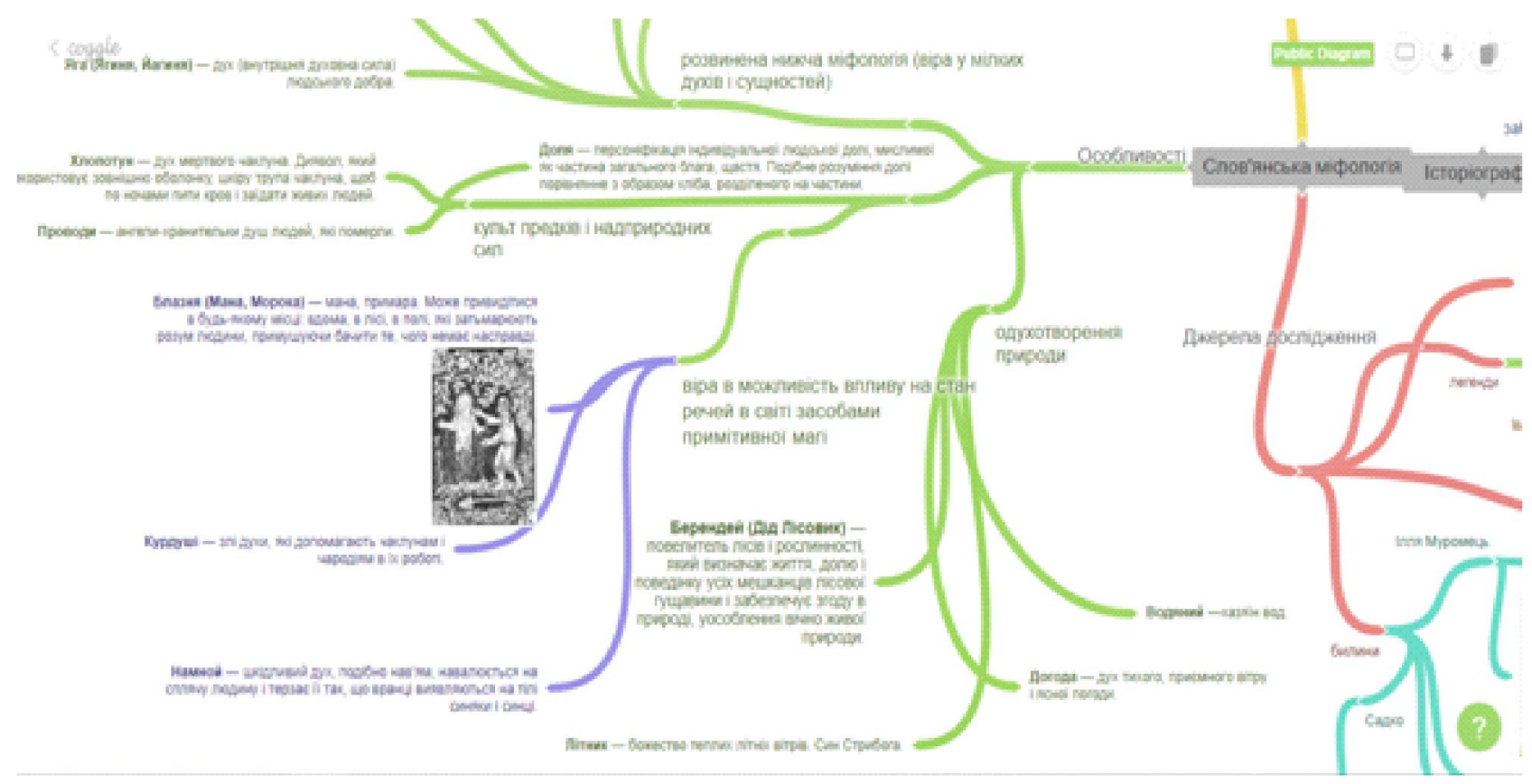

Рис. 2. Використання онлайн-сервісів Mind тар для ефективної комунікацй̈

Learning CALL) та змішане навчання надають змогу студентам отримати досвід використання автентичних матеріалів на вебсайтах. Існує безліч вебресурсів для цікавого та творчого підходу до комунікування, зосібна, онлайн-додаток для створення Mind map "карти розуму. Інтелекткарта-це логічна схема, на якій представлені всі взаємопов'язані компоненти. Нами проаналізовано використання інтелект-карт на заняттях та розроблено варіації вправ, спрямованих на творче представлення опрацьованого матеріалу, перевірку засвоєних знань тощо.

Детальніше використання онлайн-сервісів Mind map для ефективної комунікації подано на рис. 2.

Нами у процесі освітньої діяльності використовувались мобільні блоги (moblogging) - технологія соціальних мереж, таких як "спільноти однодумців", що географічно чи тимчасово обмежені й надають можливості для змістовної взаємодії. В основі блогу закладено ведення так званого "особистого онлайн-щоденника", що, у свою чергу, є корисним для ефективного комунікування, допомагає зануритися в автентичну сферу спілкування та обмінюватися досвідом. Найбільш популярними сервісами для створення блогів залишаються WordPress.com, Blogger.com, Tumblr.com.

Спробуємо проаналізувати онлайн-сервіс Wiki (змінювані вебсторінки для спільної роботи), який слу- гує платформою для онлайн-публікацій. Ідеться про спільний вебпростір, який дозволяє створювати, розміщувати та редагувати сторінки багатьом користувачам без знання вебдизайну. Wiki має подібність 3 блогом, що дозволяє швидко публікувати. Однак більш гнучка структуpa Wiki означає, що це проєктна робота, у той час як блог - як регулярний запис (Nuraryo, 2014, p. 107).

Серед мобільних соціальних мереж, призначених суго для ефективного комунікування, у тому числі й вивчення мови, найбільш популярними додатками вважаємо: Busuu, Italki, WeSpeke, Skype, Conversation Exchange, Easy Language Exchange тощо.

Щодо спілкування з іноземними студентами в соціальних мережах, то цю "дружбу" слід використовувати не суто для вивчення мови, а й для обміну культурами. Так, можна організовувати онлайн- та проєктне навчання 3 метою обміну культурною спадщиною.

Аналіз проведеної роботи допоміг нам за допомогою репрезентативного онлайн-опитування на основі системи LimeSurvey (300 респондентів) з'ясувати сформованість ефективної комунікації майбутнього викладача ЗВО. Отримані результати показали достатній рівень комунікативної толерантності (45\%). Загалом більшість майбутніх викладачів 3 повагою ставляться до життя та комунікації, у тому числі на міжкультурному просторі. Лише одиниці (10\%) 3 терпимістю або байдужістю підходять як до власної, так і інших націй, не виявляючи інтересу до соціокультурної комунікації. Результати онлайн-опитування засвідчили невисокий рівень ефективної комунікації засобами інноваційних технологій. На жаль, усього $30 \%$ респондентів зуміли ефективно комунікувати через інноваційні технології.

3 метою покращення ситуації ми впродовж двох років під час практичних занять в університеті та коледжі створювали окремі групи комунікування, працювали в них автономно. Кожна з них мала своє завдання через доступ до певних джерел інформації, ставлячи питання викладачеві. Отримані результати групи презентували у вигляді есе, електронної презентації Power Point, Google+.

Цікавими є використання технологій "Мейкерство", "Сторітеллінг", де студенти створювали власні презентації, передавали інформацію через певні стилі.

Проведені нами онлайн-проєкти відповідали певній тематиці: а) "Сімейні фестивалі в Україні, Канаді та США"; б) "Майстер розмови XXI ст.". У процесі підготовки проєктів студенти користувалися як навчальними текстами, так і матеріалами, які вони самостійно знаходили в Інтернеті.

Особливим для наших респондентів стали спеціалізовані навчальні матеріали, анімаційні пакети, наявність електронних матеріалів тощо. Уведення такої новизни, на нашу 
думку, стимулює студента, сприяє розвитку його індивідуальності. Усе ж аналіз джерельної бази показав, що країни Свропи та Америки значно ширше використовують вебресурси для навчання та ефективної комунікації молоді.

Висновки та перспективи подальших досліджень. Теоретичний аналіз проблеми дає підстави наголосити на необхідності ефективної комунікації засобами сучасних інноваційних технологій навчання. Визначено, що соціальні мережі, інформаційний простір не тільки надають вільний доступ в онлайн-мережі, а й формують соціокультурну компетентність майбутнього викладача, безпосередню комунікацію кількома мовами.

Упровадження інновацій у процесі викладання дисциплін сприяє покращенню у студентів навичок спілкування, мотивації до навчання; допомагає застосовувати методи випробування та помилок; покращує розуміння тощо.

Серед пріоритетних технологій комунікування визначено інформаційну систему Google Apps, соціальні мережі тощо. Доведена ефективність розроблених студентами медіапроектів, онлайн-блогів, організація навчання у відео-чатах та за допомогою конференцій, популярних додатків (Busuu, Italki, WeSpeke, Skype, Conversation Exchange, Easy Language Exchange тощо). Найбільш рекомендованими сервісами для створення блогів стали WordPress.com, Blogger.com, Tumblr.com. Онлайн-середовище допомагає знайти необхідну інформацію соціокультурного характеру, підштовхує до самостійного пошуку, створює та розширює міжкультурне спілкування, мотивує майбутніх викладачів.

Наше дослідження потребує подальшого напрацювання. Перспективними вважаємо вивчення особливостей використання Web-pecypсів для підвищення рівня знань студента (країнознавчих, лінгвістичних тощо) та розвитку міжкультурної комунікації у студентів загалом.

\section{СПИСОК ЛТТЕРАТУРИ}

Авраменко, В., Пархета, Л. (2019). Інноваційні технології формування мовленнєвої компетентності майбутніх педагогів. Психолого-педагогічні проблеми сучасної школи, 2 , 6-12. DOI 10.31499/27066258.2.2019.178449

Близнюк, Т. (2019). Навчальні інновації та технологічний прогрес у вивченні англійської мови: підготовка вчителя для НУШ. Освітні обрії. 2 (49). 93-96. DOI 10.15330/obrii.49.2.9396

Прокопів, Л., Корчига, Є. (2018). Інноваційні технологї удосконалення професійного розвитку майбутніх викладачів іноземної мови. Матеріали всеукр. наук.-практ. конф. "Професійна підготовка фахівців у вимірі нових освітніх реалій". ІваноФранківськ.

Шевчук, Л. (2013). Використання інноваційних технологій в процесі викладання англійської мови студентам технічних спеціальностей. Наукові записки НДУ ім. М. Гоголя. 2, 118-122.

Bonnie, B. (1992). Innovation in the professional preparation of foreign language teachers. Bulletin of the Illinois Foreign Language Teachers Association, 1, 20-27.

Brick, B. (2012). The Role of Social Networking Sites for Language Learning in UK Higher Education: The Views of Learners and Practitioners. International Journal of computerassisted Language Learning and Teaching, 2, 35-53.

Brooks, N. (1968). Teaching culture in the foreign language classroom. Foreign Language Annals, 1, 204-217.

Cambridge Academic Content Dictionary. University Press. Retrieved from https://assets.cambridge.org/ $97805213 / 18372 /$ excerpt/ 9780521318372 excerpt

Hutchinson, T., Waters, A. (1987). English for Specific Purposes (a learning-centred approach). Cambridge University Press. Retrieved from https:/ /assets.cambridge.org/97805213/18372/ excerpt/9780521318372excerpt

Nuraryo, I. (2014). Social
Networking Sites Use and Cross Cultural Adaptation of Muslim Indonesian Students in Australian Universities: Valuing Cultural Diversity. Jurnal komunikasi, 8, 2, 103-122.

\section{REFERENCES}

Avramenko, V., \& Parkheta, L. (2019). Innovacijni tekhnologhiji formuvannja movlennjevoji kompetentnosti majbutnikh pedaghoghiv. Psykhologhopedaghoghichni problemy suchasnoji shkoly, 2, 6-12. DOI 10.31499/27066258.2.2019.178449

Blyznjuk, T. (2019). Navchaljni innovaciji ta tekhnologhichnyj proghres u vyvchenni anghlijsjkoji movy: pidghotovka vchytelja dlja NUSh. Osvitni obriji, 2(49), 93-96. DOI 10.15330/obrii.49.2.93-96

Prokopiv, L., Korchygha, Je. (2018). Innovacijni tekhnologhiji udoskonalennja profesijnogho rozvytku majbutnikh vykladachiv inozemnoji movy. Materialyvseukr. nauk.-prakt. konf. "Profesijna pidghotovka fakhivciv $\mathrm{u}$ vymiri novykh osvitnikh realij". IvanoFrankivsjk.

Shevchuk, L. (2013). Vykorystannja innovacijnykh tekhnologhij v procesi vykladannja anghlijsjkoji movy studentam tekhnichnykh specialjnostej. Naukovi zapysky NDU im. M. Ghogholja, 2, 118-122.

Brooks, N. (1968). Teaching culture in the foreign language classroom. Foreign Language Annals, 1, 204-217.

Cambridge Academic Content Dictionary. Retrieved from https:// assets.cambridge.org/97805213/18372/ excerpt/9780521318372excerpt

Hutchinson, T., Waters, A. (1987). English for Specific Purposes (a learning-centred approach). Cambridge University Press. Retrieved from https:/ /assets.cambridge.org/97805213/18372/ excerpt/9780521318372excerpt

Nuraryo, I. (2014). Social Networking Sites Use and Cross Cultural Adaptation of Muslim Indonesian Students in Australian Universities. Valuing Cultural Diversity. Jurnal komunikasi, 8, 2, 103-122.

Стаття надійшла 1.04.2020 p. 